Short report

\title{
Modeling the mental health effects of victimization among homeless persons
}

\author{
Brian Edward Perron ${ }^{\mathrm{a}, *}$, Ben Alexander-Eitzman ${ }^{\mathrm{b}}$, David F. Gillespie ${ }^{\mathrm{b}}$, David Pollio ${ }^{\mathrm{c}}$ \\ ${ }^{a}$ Social Work, University of Michigan, 1080 S. University Avenue, Ann Arbor, MI 48109, United States \\ ${ }^{\mathrm{b}}$ GWB School of Social Work, Washington University, One Brookings Drive, St. Louis, MO 63130, United States \\ ${ }^{\mathrm{c}}$ Social Work, University of Alabama, 108 Little Hall, Tuscaloosa, AL 34|5487, United States
}

\section{A R T I C L E I N F O}

\section{Article history:}

Available online 12 August 2008

\section{Keywords:}

Victimization

Homelessness

Perceived safety

Depression

Structural equation modeling

USA

Mental health

\begin{abstract}
A B S T R A C T
Homeless persons are victims of violent and non-violent crime at higher rates than housed populations. While studies have suggested that victimization can induce or exacerbate mental health problems, there is very little known about factors that may buffer the effects of victimization. This cross-sectional study examined the influence of victimization on depressive symptoms in over 9600 homeless and mentally ill adults participating in the Access to Community Care and Effective Services and Supports study (ACCESS) conducted in multiple cities across the USA relationships between victimization, depressive symptoms, and perceived safety were tested within a structural equation modeling framework using data collected at the baseline interview. The overall model exhibited a good fit with the data. Non-physical victimization was associated with higher levels of depressive symptoms, and physical victimization was associated with lower levels of perceived safety. As hypothesized, perceived safety was a significant partial mediator of depressive symptoms. These results underscore the complexity of the relationships between victimization and depression in homeless adults and the importance of addressing different types of victimization in homeless and mentally ill adults.
\end{abstract}

(c) 2008 Elsevier Ltd. All rights reserved.

\section{Modeling victimization among homeless persons}

Homeless persons are victims of violent and non-violent crime at higher rates than housed populations (Fitzpatrick, La Gory, \& Ritchey, 1993; Kushel, Evans, Perry, Robertson, \& Moss, 2003; Lee, 2005). Burt (2001) reported that 22\% of homeless adults included in the 1996 National Survey of Homeless Assistance Providers had been physically assaulted and $7 \%$ reported a history of sexual assault. Within the homeless population, women appear particularly vulnerable to victimization. Homeless women are two to four times more likely to have been physically or sexually assaulted as adults when compared to housed women of similar socioeconomic status (Jasinski, Wesely, Mustaine, \& Wright, 2005). In particular, research suggests

\footnotetext{
* Corresponding author. Tel.: +1734 7639272.

E-mail address: beperron@umich.edu (B.E. Perron).
}

that women become more vulnerable once homeless (Nyamathi, Wenzel, Lesser, Flaskerud, \& Leake, 2001; Wenzel, Leake, \& Gelberg, 2000).

Prior studies also indicate that persons with mental illness are at higher risk of being victimized, and that victimization can induce or exacerbate mental health problems (Kilpatrick \& Acierno, 2003; Sorenson \& Golding, 1990). Hiday, Swartz, Swanson, Borum, and Wagner (1999) found that adults interviewed in a psychiatric inpatient unit had more than double the rate of violent victimization in the previous four months compared to the general population. Additionally, Teplin, McClelland, Abram, and Weiner (2005) demonstrated that individuals with severe mental illness had an annual rate of violent crime 11 times higher than that of the general population. Among homeless women, depression has been found to be significantly associated with victimization (Goodman, Dutton, \& Harris, 1997; Nyamathi et al., 2001; Wenzel et al., 
2000) and multiple episodes of victimization may lead to higher rates of depression, psychotic symptoms, and hospitalization (D'Ercole \& Struening, 1990).

Variability in the impact of victimization in the general population suggests the presence of factors that buffer or mediate the psychological consequences of victimization. Fullerton, Ursano, Reeves, Shigemura, and Grieger (2006), in a study of disaster workers two weeks after the 9/11 terrorist attacks, found a negative correlation between perceived safety and depression. Similarly, in a study of mental health responses to sniper attacks in the Washington, DC area, hospital staff reporting low levels of perceived safety exhibited higher depression scores (Grieger, Fullerton, Ursano, \& Reeves, 2003).

A number of studies have focused on the relationship between environmental stressors, such as perceptions of unsafe neighborhoods and depressive symptoms. Latkin and Curry (2003), for example, found that individuals who perceived their neighborhoods to have more crime and social disorganization have more reported depressive symptoms. At the same time, making connections between individual characteristics and neighborhood level data has been a particularly difficult methodological and theoretical problem (Sampson, Morenoff, \& Gannon-Rowley, 2002). To date, there have been no studies examining the association between perceptions of safety and psychiatric symptoms among the homeless population.

In examining the impact of victimization among the homeless population, researchers have found different patterns for physical versus non-physical victimization related to gender, age, and mental health status. Dietz and Wright (2005) found that younger homeless males had a higher likelihood of theft and physical assault and younger females a higher likelihood of sexual assault but that these differences in assault type did not remain in effect for the older homeless in their sample. Additionally, the mental health consequences of rape versus theft are clearly on a different level both emotionally and physically. When comparing the psychological impact of physical (in this case rape) versus non-physical (robbery), victims of physical assault have higher rates of distress (Wirtz \& Harrell, 1987) and longer recovery times (Resick, 1987). These findings suggest the need to examine the two types of victimization separately.

In contrast to the cross-sectional nature of much of the research on homelessness and victimization, Lam and Rosenheck (1998) examined the influence of victimization on psychosocial and clinical outcomes using a longitudinal design. Using multiple regression they found victimization to be positively related to the number of days of literal homelessness at 3-month and 12-month follow-ups. However, when controlling for baseline depression and other demographic variables, they found that victimization was not associated with any clinical outcomes, including depressive symptoms, psychotic symptoms, or drug use. This study is one of the first to examine these outcomes using multiple time points and provides the basis for understanding some of the more complex relationships between mental illness and victimization among the homeless.

The current study complements the work of Lam and Rosenheck (1998). More specifically, using a structural equation modeling (SEM) framework, this study examines the experience of victimization, including both physical and non-physical victimization, and its ability to predict depressive symptoms and perceived safety. Influenced by prior research, this analysis also incorporates perceived safety as a factor mediating the effects of victimization on depressive symptoms.

\section{Methods}

Sample

Data for this study were from the ACCESS program public data file $(N=13,729)$. ACCESS was an 18 -site, fiveyear project (1994-1998) intended to improve individual functioning, quality of life, and housing outcomes for homeless persons with serious mental illness (Rosenheck et al., 2002). This study used the full sample of subjects who were administered the baseline interview in the ACCESS study, which admitted new subjects each year. This procedure allowed for the largest possible sample size. The earlier cited report of Lam and Rosenheck (1998) used data from the first year of the study, which accounts for small differences in descriptive statistics. Key variables for this study were on separate assessments (i.e., intake and evaluation), and some subjects did not complete both assessments on the same day. Therefore, these subjects were excluded from the study to ensure consistency in the time frame, reducing the sample to $N=10,221$. After listwise deletion, the effective sample size for the study was $N=9643$.

\section{Measurement}

In the ACCESS assessment, subjects were queried about various types of victimization experienced during the past two months. The types of victimization included robbery by force $(10.4 \%)$, theft of property $(28.0 \%)$, threats with a weapon (16.2\%), physical assault (14.9\%), and sexual assault (4.8\%). The types of victimization were sorted into two categories: physical victimization (robbery by force, physical assault, and sexual assault) and non-physical victimization (theft of property and threats with a weapon). Each type was dichotomously scored, reflecting whether or not any types of the victimizations were experienced during the past two months.

Depressive symptoms were measured with items that were derived from the Diagnostic Interview Schedule (Robins, Helzer, Croughan, \& Ratcliff, 1981) and Psychiatric Epidemiology Research Interview (Dohrenwend, 1982). In the ACCESS assessment, one item was used as a screening question to identify subjects who had depressive feelings that occurred during the past month. Specifically, subjects were queried: "In the past month, have you had at least a two-week period when you felt extremely sad, depressed or blue every day or when you lost all interest and pleasure in things you usually cared about or enjoyed?" Response items included, "No," "Yes," and "Yes, under the influence of alcohol or drugs."

Subjects who endorsed "Yes" and did not report the experience occurring under the influence of alcohol or 
drugs were asked four follow-up questions, which were regarded as candidate items for the depressive symptoms measurement model. The specific items included: trouble concentrating; thoughts about death; feelings of worthlessness, sin or guilt; and feelings of restlessness. The items also applied the past-month alcohol and drug induced exclusionary criterion.

Five survey items from the Lehman Quality of Life Instrument were used to operationalize 'perceived safety.' These items focused on satisfaction with personal safety; safety on the streets; safety where one lives; protection you have against being robbed or attacked; chances of finding a police officer if you needed one. All responses were on a 7 -point Likert-type rating scale ( $1=$ terrible, $7=$ delighted).

\section{Analytic strategy}

The primary analytic strategy for this study was structural equation modeling (SEM). The fit of the latent variables (depressive symptoms and perceived safety) using confirmatory factor analysis was examined first, prior to examining the full model. Multiple group comparisons were also conducted to see whether the models exhibited differences across population subgroups. Because the data included dichotomous indicators, polychoric correlations were computed and models were estimated using diagonally weighted least squares (Jöreskog \& Sörbom, 1993). The adequacy of model fit was determined using multiple fit measures, including the chi-square $\left(\chi^{2}\right)$ test, root mean square error of approximation (RMSEA), comparative fit index (CFI), and goodness of fit index (GFI). Given the large sample size, interpretations of coefficients were made based on effect size rather than statistical significant. An effect size of least $|.10|$ was considered clinically significant.

\section{Results}

\section{Sample description}

The average age of the subjects was 38.5 years $(\mathrm{SD}=9.6)$. Approximately $60 \%$ of the subjects were male. The majority of the sample was either non-Hispanic Black (46\%) or non-Hispanic White (44\%). Over half the subjects self-reported a current episode of homelessness of less than six months. Fifty-five per cent had a substance use disorder, and $50 \%$ psychotic features.

Approximately $22 \%$ of the subjects reported physical victimization. The most common type of physical victimization was physical assault (15\%). Approximately 35\% of subjects reported non-physical victimization. The most common types of non-physical victimization included theft of property (28\%) and threats with a weapon (16\%). Theft of property and threats with a weapon comprised the measure of non-physical victimization.

At baseline, over half the subjects reported experiencing at least one of the three depressive symptoms. Having trouble concentrating was the most common (70\%), followed by feelings of worthlessness (69\%) and thoughts about death (59\%). Mean values on items measuring perceived safety ranged from 3.4 to 4.1 . Inter-correlations among these items ranged from .30 to .64 .

\section{Structural equation modeling}

The latent variables, depressive symptoms and perceived safety, were tested using confirmatory factor analysis. The models exhibited a good fit. All factor loadings were greater than the minimum expected value of .70, except one of the perceived safety variables (i.e., chances of finding a police officer; factor loading $=.45$ ). This variable was excluded from the analysis. The fit of the final baseline measurement model was as follows: $\chi^{2}(13)=187.77, \quad$ RMSEA $=.037 \quad(90 \% \quad C I=.033-.042)$, $\mathrm{CFI}=1.0, \mathrm{GFI}=1.0$. The full SEM also exhibited a good fit with the data: $\chi^{2}(23)=201.74, \quad$ RMSEA $=.028 \quad(90 \%$ $\mathrm{CI}=.025-.032), \mathrm{CFI}=1.0$, and $\mathrm{GFI}=1.0$.

The parameter estimates of the model are summarized in Fig. 1. Path relationships were significant if their coefficients (i.e., effect sizes) were larger than |.10|. This figure shows that physical victimization was significantly associated with lower levels of perceived safety but not directly associated with depressive symptoms. On the other hand, non-physical victimization was not associated with perceived safety but was associated with higher levels of depressive symptoms. Perceived safety was negatively associated with depressive symptoms, with a relatively large effect size compared to the other structural coefficients.

Using multiple group comparisons, additional analyses were conducted to determine the stability of the model across groups stratified by age, ethnicity, gender, length of time homeless, presence of a substance use problem, and presence of a psychotic disorder. Small differences in path relationships were observed. However, none of the coefficients changed directions, and all effect sizes were within a value of $|.12|$ relative to the baseline model. For example, in the gender comparison, the path from physical victimization to perceived safety, and the path from non-physical victimization to depressive symptoms were nearly identical in the baseline model and multiple group comparison. The non-physical and physical victimization paths that were non-significant in the baseline model remained non-significant for females in the multiple group comparison. For males, this path reached statistical significance, but the effect size was small $(\beta=-.11)$. The path from perceived safety to depressive symptoms also showed very small differential effects across males and females in the multiple group comparisons $(\beta=-.46$ and -.39 , respectively), but these differences have no real practical significance. The full set of comparisons across all groups is available from the first author.

\section{Discussion}

The purpose of this study was to examine the association between victimization and depression and test whether this association is mediated by perceptions of safety. This study is the first to examine the associations among victimization, perceived safety and depressive symptoms among a homeless population. The model 


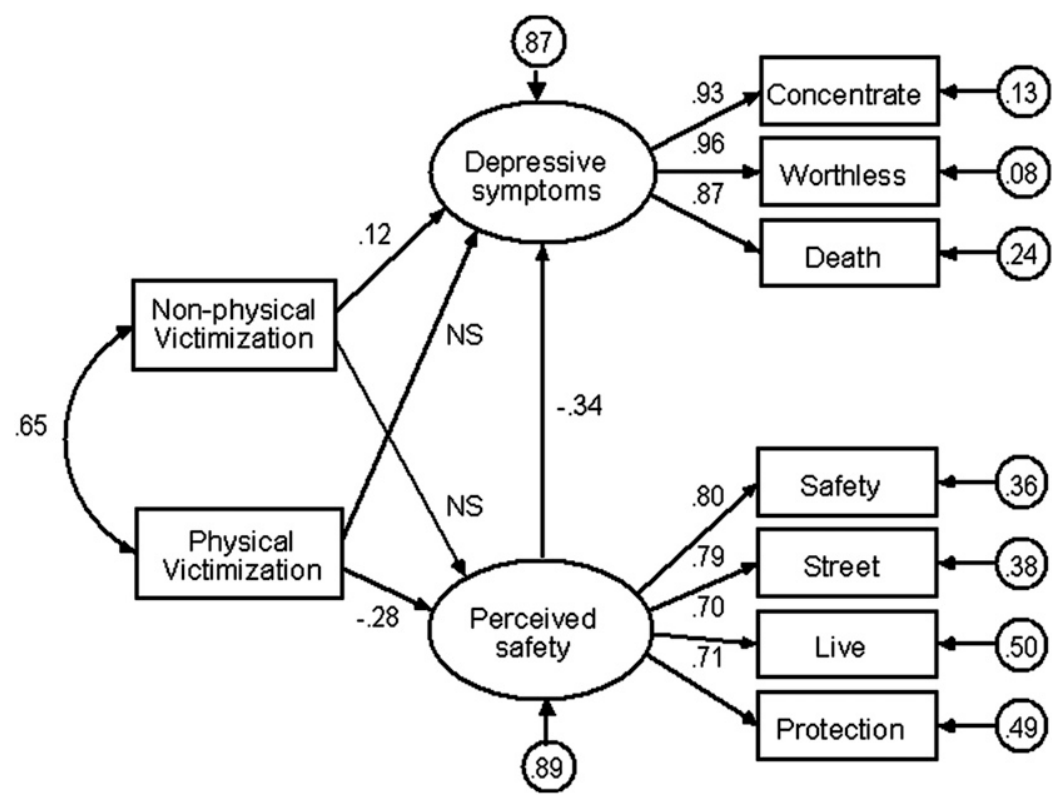

Fig. 1. Structural equation model representing the influence of victimization on depressive symptoms with perceived safety as a partial mediator. Note: overall model exhibited a good fit with the data: $\chi^{2}(23)=201.74$, RMSEA $=.028(90 \% \mathrm{CI}=.025-.032)$, CFI $=1.0$, and GFI $=1.0$. Structural coefficients were considered significant if the values exceed an effect size of $|.10|$. NS $=$ non-significant.

showed that non-physical victimization had a significant direct effect on depressive symptoms while physical victimization did not. Differences with Lam and Rosenheck's (1998) report of no direct association between victimization and depression in a multivariate model controlling for depression and a number of other baseline variables should be interpreted in light of several key methodological distinctions. The current study measured victimization differently, included all baseline interviews collected over the five years of the study, and analyzed these relationships within a structural equation modeling framework.

The lack of significant direct associations between physical victimization and depressive symptoms in a homeless, service-using population contrasts with findings from the Epidemiologic Catchment Area Surveys of housed adults where both physical victimization and non-physical victimization were associated with reported depressive symptoms (Sorenson \& Golding, 1990). One possible reason for this difference among homeless persons in the ACCESS study is that, as Fitzpatrick et al. (1993) contend, the mental health effects of victimization are masked by the overwhelming circumstances of being homeless. At the same time, the results of this study support the possibility of an indirect relationship between physical victimization and depression, mediated by perceived safety as is discussed below. Minimally, these findings suggest that the trauma experienced disproportionately among the homeless population is being impacted specifically by individual's current housing status.

Physical victimization was associated with lower levels of perceived safety, but non-physical victimization was not. One possibility is that persons living on the streets experience non-physical victimization as a routine part of life on the streets. This is supported by the fact that there was little difference in values for perceived safety in this population when compared to other studies of homeless (Lehman, Kernan, DeForge, \& Dixon, 1995) and non-homeless mentally ill adults (Lehman, 1992; Macias, Young, \& Barreira, 2000). On the other hand, physical victimization may be associated with greater trauma and, therefore, having a greater influence on how one perceives her or his immediate environment. Taken together, these data suggest that, while there appear to be some small differences in response to victimization within the homeless population, perceived safety appears to be an important mediating factor, particularly among those with a recent history of physical victimization.

The patterns of association observed in this study were consistent with prior studies examining the associations between trauma, perceived safety, and mental health functioning in other populations, including mental health service providers (Fullerton et al., 2006; Grieger et al., 2003). This suggests that the influences of trauma, victimization, and other highly stressful experiences have consequences for multiple populations.

It is important to consider the results within the context of the study limitations. The measures of victimization were based on dichotomous indicators, reflecting only the presence or absence of different forms of victimization over a specific period of time. This approach is limited because it does not take into account the severity or occurrences of victimization. Similarly, the indicators of depressive symptoms were also dichotomously scored and do not capture the full range of depressive functioning. Using a standardized scale that would allow for a rating of severity on each indicator is necessary to develop a complete empirical picture. Because of the cross-sectional 
nature of our data, it is not possible to establish causality or temporal ordering between victimization and depressive symptoms. For example, while the literature suggests that victimization leads to depressive symptoms, it is possible that one's mental health status may make a person a target of victimization. Finally, the findings of this study are limited to only service-using homeless persons who are diagnosed with a serious mental illness. It is unknown whether these associations generalize to the broader homeless populations that are disconnected from the service population. As a last point, interpretation of these results must take into account that all the associations in this model were cross-sectional in nature and should not be understood to imply that there is necessarily a temporal causal relationship between victimization, perceived safety, and depressive symptoms.

Despite limitations, this study can serve as a basis for future research on victimization among the homeless population. Future research using a longitudinal approach with a large sample and improved measurement is necessary to further understand the consequences of victimization. This would show how the consequences of victimization change over time and clarify how long services and treatment may be necessary following the occurrence of victimization. Future research should also consider the possibility of more complex relationships among perceptions of safety and depressive functioning. Specifically, it is possible that perceptions of safety both influence and are influenced by depressive functioning. The model developed in this study provides an excellent basis for extending it to include feedback relationships to capture such complexities.

\section{References}

Burt, M. R. (2001). What will it take to end homelessness? Washington, DC: Urban Institute.

D'Ercole, A., \& Struening, E. (1990). Victimization among homeless women: implications for service delivery. Journal of Community Psychology, 18(2), 141-152.

Dietz, T. L., \& Wright, J. D. (2005). Age and gender differences and predictors of victimization of the older homeless. Journal of Elder Abuse $\mathcal{E}^{\circ}$ Neglect, 17(1), 37-60.

Dohrenwend, B. P. (1982). Psychiatric epidemiology research interview (PERI). New York: Columbia University, Social Psychiatry Research Unit.

Fitzpatrick, K. M., La Gory, M. E., \& Ritchey, F. J. (1993). Criminal victimization among the homeless. Justice Quarterly, 10(3), 353-368.

Fullerton, C. S., Ursano, R. J., Reeves, J., Shigemura, J., \& Grieger, T. (2006). Perceived safety in disaster workers following 9/11. The Journal of Nervous and Mental Disease, 194(1), 61-63.

Goodman, L. A., Dutton, M. A., \& Harris, M. (1997). The relationship between violence dimensions and symptom severity among homeless, mentally ill women. Journal of Traumatic Stress, 10(1), 51-70.
Grieger, T. A., Fullerton, C. S., Ursano, R. J., \& Reeves, J. J. (2003). Acute stress disorder, alcohol use, and perception of safety among hospital staff after the sniper attacks. Psychiatric Services, 54(10), 1383-1387.

Hiday, V. A., Swartz, M. S., Swanson, J. W., Borum, R., \& Wagner, H. R. (1999). Criminal victimization of persons with severe mental illness. Psychiatric Services, 50(1), 62-68.

Jasinski, J. L., Wesely, J., Mustaine, E., \& Wright, J. D. (2005). The experience of violence in the lives of homeless women: A research report. Washington, DC: National Institute of Justice.

Jöreskog, K. G., \& Sörbom, D. (1993). LISREL 8: Structural equation modeling with SIMPLIS command language. Lincolnwood: Scientific Software International.

Kilpatrick, D. G., \& Acierno, R. (2003). Mental health needs of crime victims: epidemiology and outcomes. Journal of Traumatic Stress, 16(2), 119-132.

Kushel, M. B., Evans, J. L., Perry, S., Robertson, M. J., \& Moss, A. R. (2003). No door to lock: victimization among homeless and marginally housed persons. Archives of Internal Medicine, 163(20), 2492-2499.

Lam, J. A., \& Rosenheck, R. (1998). The effect of victimization on clinical outcomes of homeless persons with serious mental illness. Psychiatric Services, 49(5), 678-683.

Latkin, C. A., \& Curry, A. D. (2003). Stressful neighborhoods and depression: a prospective study of the impact of neighborhood disorder. Journal of Health and Social Behavior, 44(1), 34-44.

Lee, B. A. (2005). Danger on the streets - marginality and victimization among homeless people. American Behavioral Scientist, 48(8), 10551081.

Lehman, A. F. (1992). Quality of life experiences of the chronically mentally ill: gender and stages of life effects. Evaluation and Program Planning, 15(1), 7-12.

Lehman, A. F., Kernan, E., DeForge, B. R., \& Dixon, L. (1995). Effects of homelessness on the quality of life of persons with severe mental illness. Psychiatric Services, 46(9), 922-926.

Macias, C. M., Young, R., \& Barreira, P. (2000). Loss of trust: correlates of the comorbidity of PTSD and severe mental illness. Journal of Loss and Trauma, 5(2), 103-123.

Nyamathi, A., Wenzel, S. L., Lesser, J., Flaskerud, J., \& Leake, B. (2001). Comparison of psychosocial and behavioral profiles of victimized and nonvictimized homeless women and their intimate partners. Research in Nursing \& Health, 24(4), 324-335.

Resick, P. A. (1987). Psychological effects of victimization: implications for the criminal justice system. Crime \& Delinquency, 33(4), 468-478.

Robins, L. N., Helzer, J. E., Croughan, J., \& Ratcliff, K. S. (1981). National institute of mental health diagnostic interview schedule. Its history, characteristics, and validity. Archives of General Psychiatry, 38(4), 381-389.

Rosenheck, R. A., Lam, J., Morrissey, J. P., Calloway, M. O., Stolar, M., Randolph, F., et al. (2002). Service systems integration and outcomes for mentally ill homeless persons in the ACCESS program. Access to community care and effective services and supports. Psychiatric Services, 53(8), 958-966.

Sampson, R. J., Morenoff, J. D., \& Gannon-Rowley, T. (2002). Assessing "neighborhood effects": social. Annual Review of Sociology, 28, 443478 .

Sorenson, S. B., \& Golding, J. M. (1990). Depressive sequelae of recent criminal victimization. Journal of Traumatic Stress, 3(3), 337-350.

Teplin, L. A., McClelland, G. M., Abram, K. M., \& Weiner, D. A. (2005). Crime victimization in adults with severe mental illness: comparison with the national crime victimization survey. Archives of General Psychiatry, 62(8), 911-921.

Wenzel, S. L., Leake, B. D., \& Gelberg, L. (2000). Health of homeless women with recent experience of rape. Journal of General Internal Medicine, 15(4), 265-268.

Wirtz, P. W., \& Harrell, A. V. (1987). Assaultive versus nonassaultive victimization: a profile analysis of psychological response. Journal of Interpersonal Violence, 2(3), 264-277. 